pearlyte surrounded by a mesh-work of cementite.
The latter, then, differs from the former in having cementite, the carbide of iron, for a mesh-work instead of ferrite, the pure carbonless iron $;$ and the propor-
tion of carbon in the whole mass of the metal is naturally much larger in the metal which has cementite than Now these minerals are only recognized in metal which has been slowly cooled, that is annealed. In suddenly seem to have a single substance, corresponding to
obsidian, for which I suggest the name hardenite. And it is doubtful whether the waves of light are suffi ened steel to be seen. Here, then, we have a most marked change in the very nature of steel caused by sudden cooling from a high temperature.
This enables us to understand what is called the statu quo theory of the hardening of steel. We have seen tain critical point, certain very marked changes occur suddenly, a great quantity of heat is absorioe, and what seems to be a new metal arises. If we cool the
steel slowly, these changes are reversed as the temperature sinks back past a certain critical point, and our properties the same as before heating.

The status que theory is that the change, call it chemical or physical, allotropic or molecular, or what ening; that above certain temperatures the metal, passes automatically into a new state, the hard state, tensely hard. If we cool slowly, the metal changes
back from the hard to the soft state; its initial properback from the hard to the soft state; its initial proper-
ties are regained; but thischange takes time, and if we ties are regained; but thischange takes time, and if we
cool very fast, the metal remaing in the hard state
simply because the rapid cooling denies it the time necessary for the change from hard to soft. In tempering we reheat the metal gently to a range of tem-
peratures in which the change from hard to soft can occur ; $i$. e., this gentle reheating offers the metal time
to make the change which it tended to make, but had to make the change which it tended to make, but had facts well enough to warrant my bringing them before

As the changes in the magnetic and thermo-electric properties, the crackling sound, the absorption of heat ture rises above certain eritical points, $\mathrm{V}$ and $\mathrm{W}$, it follows that if the sudden cooling causes hardness by
preserving the new compound which is formed when these phenomena occur, then we should find that sudunless it takes place from a temperature above $V$ and
iV. And this is the case.

The hardness produced by quenching is by no means a simple function of the temperature from which higher temperatures, the hardness of the quenched higher temperatures, the hardness of the quenched
steel does not increase markedly till a certain critical
temperature is reached ; with slight further increase of temperature the hardness rises rapidly, apparently nearly to a maximum. To illustrate. We have here a
series of pieces which were originally contiguous parts
of a steel bar. This bar was heated in such a manner that the temperature declined extremely gradually from one
end to the other. One end was at a full yellow heat,
the other was but end to the other. One end was at a full yellow heat,
the other was but little below visible redness. There
nay have been a difference of somewhere about $600^{\circ} \mathrm{C}$. in a length of 12 in., or of $50^{\circ}$ per inch. Now when this bar had been thus heated, it was suddenly drawn and
instantly quenched in cold water. Examining its hardness with the file, and passing from the cool to-
ward the hot end, we find that the hardness does not ward the hot end, we till we reach a point about 4 in.
change appreciably til the hot
from t in the next inch and a half, covering possibly $150^{\circ} \mathrm{C}$., the hardness rises to an apparent maximum. In certain cases I have known this to oc-
cur in a distance of $3 / 8$ of an inch. This sudden increase of hardness occurs jist where the size of the grain sud-
denly diminishes, that is to say at the temperature, $\mathrm{W}$; and both these changes are apparently simultaneous bon. All through the soft part of the bar the carbon
is in the non-luardening state; but just where the bar changes from soft to hard, and the grain from coarse to fine, there the carbon changes from non-harden-
ing to hardening. I must add, however, that the ing to hardening. I must add, however, that the change and the fracture change now rests on the evidence of the nitric acid spotting test and that we are indications of the condition of carbon.

Whatever may be the true explanation, the fact re-
mains that after sudden cooling we have glasshardness
where we had relative softness: extreme brittleness in stead of toughness: did not have before; a new condition of carbon ; lower ently homogeneous substance, where before we had

composite, granite-like mass.
There is one important effect of sudden cooling to
which I have not yet referred-stress. You are all fauniliar with the stress which exists in
suddenly cooled glass, exemplified in the well-known suddenly cooled glass, exemplified in the well-known
toy, Prince Rupert's drop. A little molten glass is dropped in water, the outer shell solidifies and becomes cooling from this point the interior has farther to coo than the shell, and hence tends to contract more in this, and the interior remains in a state of violent tension, the exterior in a state of compression. As long as
the forces are balanced, no resultant occurs. But if we thestroy the balance by breaining the skin in one spot, the internal stress tears the ball to pieces.

In the case of suddenly cooled steel we have similar.
conditions. Sir Frederic Bramwell tells of a friend who was visiting a factory where projectiles, which was warned not to go into a certain shed, as those flew with very considerable violence. One would at first suppose that the explosion of loaded projectiles possible. In carrying out the manufacture, the iron or
was referred to, but it was simply the cracking lof the steel is melted, and the required proportion of commer-
hardened shells, flying to pieces from their internal cial nickel is added. The resulting alloy may either be hardened shells, flying to pieces from their internal! cial nickel is added. The resulting alloy may either be

The stress induced by sudden cooling may readily be
eerified by destroying the balance of stress by eliminating part of it, as, for instance, by slitting a harden
ed piece longitudinally, its fragments immediately warp out of shape. A still easier way is to harden
bundle of steel strips tightly inclosed in a copper box

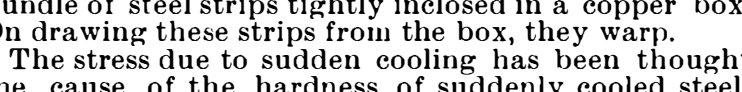
the cause of the hardness of suddenly cooled steel
But while the stress, in a general way, increases with the hardness, there are so many apparent exceptions by sudden cooling is doubtless one cause of the peculi-
arities of hardened steel.

We thus have two apparently distinct simultaneou
effects of sudden cooling-the preservation of a hard brittle substance formed at the critical temperature $\mathrm{W}$, and the formation of stress, which, according to it and may greatly reduce or almost destroy the strength. sufficiently plastic to prevent severe stresses from aris-
ing. You cannot have severe stress in soft molasses to non-hardening, and the hardness and brittleness
which it causes can be thus removed. Finally, there is ery little tendency to crystallize below V.
Our safe channel is this : If you wish to cool you preserve the porcelanie grain formed at $W$, or if you t a high temperature, so as to prevent the grain from Arowing coarse during slow cooling, simply do this ow V no serious crystallization will form; at or slightly below $V$ no serious stress will exist. Below $V$ your car
bon will change from hardening to non-hardening, and dangerous and costly ; dangerous becausethe complete while by the methods I have described the heat which whe metal still contains when its sudden cooling has
been interrupted at $V$ suffices for tempering or anneal stress which sudden coolirg has set up, $i$. $e_{\text {., t }}$ emper, let us remember that this tempering is but one
orm of annealing, a aming to remove stress and to en-
able the carbon to change from the hardening to the ble the carbon to change from the hardening to the
on-hardening state. To accomplish these things we
ond not heat highly. At $\mathrm{V}$ it is probable that all bovere stress is removed in most cases, and that the carhings, and, if carried materially above W, it will again But toughness, sof tness, and freedom from stress. the initial stresses intentionally introduced in ordnance manufacture. A moderate amount of hardening car-
bon, while diminishing the toughness, inereases the trength greatly. For many purposes, then, we seek moderate stress and moderate hardness. For such pur-
poses the methods which I have sketched may be
modified by carrying the sudden cooling to slightly By varying the rate of cooling and the range of temthe resulting stress and the proportion of the carbon which remains in the hardening state, while preserving rate and a range of cooling most fitted for one pur-
pose and for steel of given composition may not be the best for other conditions and other steels. To needs of the object we are making will be a difficult
but not necessarily a very difficult task, once the gentreatment, much closer control of temperature is
needed than we have at present. 'To-day we rely on the eye exclusively. We need not only greater know-
ledge, but the problem inust be studied with the pyrometer, with the microscope, with the testing machine, This problem I believe to be the one which to-day
presses the steel maker and user most closely. May
you and I not only live to see, but may we hasten its solution.

\section{A NEW NICKEL ALLOY.}

By' J. T. HA Lu, Sheffield.

THE alloy is formed by the addition of from $21 / 2$ to 50 steel. The properties which are obtained by this inixture are a close grain, great strength and toughness, it is intended for employment in the manufacture of
shells, gun barrels, armor plates, etc. The steel may contain carbon, silicon, chromium, tungsten, manis preferable to reduce their proportions as much as
is a

\section{HYIDRAZINE.} it may, furthermore, actually crack the metal, or greatly distort it.
On account of these effects we have not, in general, availed ourselves of the fact that sudden cooling from $\mathrm{W}$ preserves the ine grain set up when steel is heated
to $\mathrm{W}$; or of the fact that sudden cooling applied the moment that forging ceases preserves the fine grain which would take place during slow cooling after forg-
ng had ceased, the coarseness of grain our Scylla, the brittleness, and even the formation of fissures, our
Charybdis. What, then, is our safe channel? At V Charybdis. What, then, is our safe channel? At $V$,
nd at temperatures slightly below it, the metal is still
ufficiently plastic to prevent severe stresses from arisandy; it yields to the stress. Further, at temperatures
but slightly below V, our hardening carbon can change our steel, when cooled, will be fine-grained, will be
ree from stress, will be soft and tough.
Another course is to cool suddenly and completely,
and then to reheat, as in tempering common tools Another course is to cool suddenly and completely,
and then to reheat, as in tempering common tools
of steel. But for large and costly pieces, this may be

ing it.
If, however, the metal has been suddenly and com-
pletely cooled, and if we wish to remove the hardness lead to coarseness of grain.
Up to this point I have assumed that we sought but not necessirily a very difficult task, once the gen-
eral principles which govern us are clearly grasped.
To arrive at great excellen ce in these methods of heatIs the course of investigations on the diazo and azo compounds of the fatty series. Th. Curtius and J.
Lang* have shown that when the ethyl salt of diazotrated aqueous solution of caustic alkali, a salt of triazo-acetic acid, $\mathrm{C}_{3} \mathrm{H}_{3} \mathrm{~N}_{6}(\mathrm{COOH})_{3}$ is formed. 'This acid
is stable in the free condition, and when boiled with mineral acids it gives up its nitrogen in the form of hy-
drazine, $N_{2} \mathrm{H}_{4}$. The main reaction involved is that redrazine, $\mathrm{N}_{2} \mathrm{H}_{4}$. 'The main
presented in the equation :

$\mathrm{C}_{3} \mathrm{H}_{3} \mathrm{~N}_{6}(\mathrm{COOH})_{3}+6 \mathrm{H}_{2} \mathrm{O}=3 \mathrm{C}_{2} \mathrm{O}_{4} \mathrm{H}_{2}+3 \mathrm{~N}_{2} \mathrm{H}_{4}$

The exalic acid, which is the other product of the re
ction, is, however, more or less completely transformed into carbon dioxide and formic acid-a fact which is ex

$\mathrm{C}_{3} \mathrm{H}_{2} \mathrm{~N}_{6}(\mathrm{COOH})_{3}+6 \mathrm{H}_{2} \mathrm{O}=3 \mathrm{CO}_{2}+3 \mathrm{HCOOH}+3 \mathrm{~N}_{2} \mathrm{H}_{4}$

$\mathrm{Hydrazine}$ is formed also by the following reactions
1 . $\mathrm{By}$ reduction of ethyl diazo-acetate by zinc dust and acetic acid, $t$ or by aluminum or zine filings in alka 2. By boiling with water the addition products which
line soliond, the ethereal salts of diazo-acetic acid form with the The decomposition of triacids.

by far the best method for preparing hydrazine. 'The
. ield is about 90 per cent. of the theoretical.

$T h$. Curtius and R. Jay $\ddagger$ have made hydrazine and its hivatives the subject of an extensive investigation
he results of which are briefly summarized in this note As regards the quantities with which they worked,
an experiment is described in which they treated 245 an experiment is described in which they treated 24.5
grms. of triazo-acetic acid in two liters of water with 300 pure hydrazine sulphate was deposited in colorless crystals. On evaporating the mother liquor, a second deposit of the sulphate was obtained. From the last mother liquors the remaining hydrazine was extracted an insoluble compound of the formula $\mathrm{N}_{2}\left(\mathrm{CH}_{2} \mathrm{C}_{6} \mathrm{H}_{6}\right)_{2}$. then obtained by treating with sulphuric or hydro$\left(\mathrm{C}_{6} \mathrm{H}_{6} \mathrm{CH}\right)_{2} \mathrm{~N}_{2}+2 \mathrm{H}_{2} \mathrm{O}+\mathrm{H}_{2} \mathrm{SO}_{4}=$

Hydrazine combines with one or two molecules of monobasic acids to form stable salts. Even in acid
solucion these have extraordinary reducing power, the heated alone they decompose at a high temperature, forming ammonium salts, nitrogen, and hydrogen.
When a nitrite is added to hydrazine salts, nitrogen is rapidly evolved. Of the salts thus far examined, only
the sulphate is difficultly soluble in water. The salts re either insoluble or but slightly soluble in alcohol. appear to be isonorphous with the corresponding annmonium salts. The physical properties of hydzazine tself are as yet unknown. It appears from what has
thus far been learned that it is a gas or a liquid boiling t a low temperature.

That its molecular weight is correctly represented by the formula $\mathrm{N}_{2} \mathrm{H}_{4}$ follows from the existence of the two
hydrochloric acid salts, $\mathrm{N}_{2} \mathrm{H}_{4} . \mathrm{HCl}$ and $\mathrm{N}_{2} \mathrm{H}_{4} .2 \mathrm{HCl}$, and aiso from the results obtained in determining the mo-
ecular weight of benzalazine by Raoult's method. The
compound has a remarkable affinity for water, and orms a hydrate of the composition $\mathrm{N}_{2} \mathrm{H}_{4}+\mathrm{H}_{2} \mathrm{O}$. As in in
ettting hydrazine free from its salts it is necessary to use the oxides or hydroxides of the alkali metals or of arily formed in the reaction, thin,

$\mathrm{N}_{2} \mathrm{H}_{4}(\mathrm{AH})_{2}+\mathrm{M}_{2} \mathrm{O}=\mathrm{N}_{\mathbf{2}} \mathrm{H}_{4}+\mathrm{H}_{2} \mathrm{O}+2 \mathrm{MA}$

it follows that hydrazine is always obtained in the form of the hydrate. An attempt was made to break up this and quicklime from a silver vessel, and passing the volatile product through a silver tube filled with pieces
of quicklime. No gas was obtained, and only a snall quantity of a liquid came over. This proved to be hydrazine hydrate. It was shown further that barium
oxide has not the power to decompose hydrazine hy rate into water and hydrazine.
A large quantity of the hydrate has been made by istilling the sulphate with potassium hydroxide fron regard to this remarkable compound will be given in ater article by Curtius and Schulz. Meanwhile the
following is all that is said concerning it. It has the composition $\mathrm{N}_{2} \mathrm{H}_{4}+\mathrm{H}_{2} \mathrm{O}$, and forms a colorless, inodorin the air and boils without change at $119^{\circ}$. Pure hy the boiling temperature it attacks glass strongly, and estroys cork and rubber. It has an alkaline taste, and extremely active poison for lower organisms. It is an Hydrazine is the strongest reducing agent known. $\Lambda$ eutral solution of platinic chloride is reduced to metallic platinum, which separates in beautiful pieces
having a silver luster, or in the form of a mirror. In acid solution, on the other hand, platinic chloride is reuced only to platinous chloride. In the same way
hydrazine hydrate precipitates all easily reducible metals in the cold. Silver separates in compact lus-
trous pieces, apparently of crystalline structure. With very dilute solutions most perfect mirrors of great beauty are obtained. From aluminum the hydroxide there is first formed a yellow colored double salt, from which metallic mercury soon separates. In acid solucupric to cuprous chloride. I)ropped upon mercuric oxide or quinone, hydrazine hydrate canses an explo-
ion. The facts inentioned show that this-ubstance is undoubtedly destined to play an extraordiuarily in portant part in anilytical chemistry, and extensive in-
vestigations are now in progress with reference to its
applications in this fleld.-1. R., in Amer. Chem. 